\title{
REDUÇÃO DA TRANSMISSÃO VERTICAL DO HIV: DESAFIO PARA A ASSISTÊNCIA DE ENFERMAGEM*
}

\author{
Maria José Rodrigues Vaz** \\ Sonia Maria Oliveira de Barros***
}

VAZ, M.J.R.; BARROS, S.M.O. Redução da transmissão vertical do HIV: desafio para a assistência de enfermagem.

Rev.latino-am.enfermagem, Ribeirão Preto, v. 8, n. 2, p. 41-46, abril 2000.

Com as crescentes taxas de infecção pelo HIV na população feminina em idade fértil podemos observar um aumento correspondente de infecções congênitas. A enfermeira obstetra deve, portanto, estar atualizada para a participação e desenvolvimento de programas de assistência pré-natal às gestantes portadoras do HIV. Este trabalho tem como objetivo fornecer uma revisão sobre o acompanhamento pré-natal desta população para a assistência de enfermagem. Não se pretende esgotar o assunto, uma vez que pesquisas ampliam os enormes avanços já ocorridos desde o reconhecimento da doença.

UNITERMOS: HIV, síndrome da imunodeficiência adquirida, cuidado pré-natal, enfermagem obstétrica

\section{INTRODUÇ̃̃̃O}

Este é um trabalho de atualização sobre a redução da transmissão vertical do vírus da imunodeficiência humana (HIV), um dos grandes desafios para a assistência de enfermagem no próximo milênio. Tem como objetivo fornecer uma revisão sobre o acompanhamento pré-natal de gestantes portadoras do HIV a fim de instrumentalizar as enfermeiras na sua prática assistencial.

Desde o seu reconhecimento, a AIDS sofreu várias mudanças conceituais. Inicialmente, as pessoas infectadas tinham em comum o fato de serem jovens, saudáveis, a maioria homossexual e alguns usuários de drogas endovenosas. Pouco tempo depois, a AIDS já não era restrita ao grupo dos homossexuais ou bissexuais, sendo identificados casos entre usuários de drogas endovenosas, hemofílicos, parceiros heterossexuais de portadores do HIV e receptores de sangue ou seus derivados (MARIN et al.,1991).

A infecção pelo HIV é, atualmente, um grave problema no contexto da Saúde Pública, de caráter pandêmico, com evolução letal e para a qual não existe, ainda, tratamento curativo ou vacina. Além disso, é uma doença cercada de mitos e preconceitos morais e sociais, que podem afetar o aspecto psicológico, as relações familiares, afetivas, sociais e profissionais do portador.

O HIV é um lentivírus, pertence à família dos retrovírus e apresenta tropismo seletivo para o sítio receptor $\mathrm{CD} 4+$ do linfócito $\mathrm{T}$ humano, levando a alterações do sistema imunológico, defeitos na imunidade celular em conseqüência da redução do número de células $\mathrm{T}$, da destruição celular e de defeitos qualitativos no seu funcionamento (TURGEON, 1996).

O quadro epidemiológico da AIDS no Brasil vem apresentando modificações importantes, tanto na forma de transmissão quanto no perfil dos portadores. Paralelamente à redução dos casos entre homossexuais e bissexuais masculinos, ocorreu aumento proporcional, no total de casos notificados, entre heterossexuais com idade superior a 12 anos. Na distribuição dos casos segundo o sexo, encontramos em 1983 a razão homem:mulher de 17:1, e em 1997, 2:1. Desde as primeiras notificações de casos de AIDS entre as mulheres, em 1983, do total de casos, a maioria $(77,5 \%)$ encontra-se na faixa etária de 20 a 44 anos (BRASIL, 1998a) coincidindo, portanto, com o período reprodutivo das mulheres.

A progressão da AIDS entre as mulheres tem, como conseqüência, o número crescente de casos em

\footnotetext{
* Trabalho extraído da Tese de Mestrado "Assistência de Enfermagem às Gestantes Portadoras do Vírus da Imunodeficiência Humana: Levantamento de Dados e Diagnósticos de Enfermagem" apresentada ao Programa de Pós-Graduação em Enfermagem, na área de Enfermagem Obstétrica, UNIFESP/EPM, 1998 e vinculado ao Projeto Integrado de Pesquisa do CNPq n 522552/95 ** Enfermeira Obstetra. Mestre em Enfermagem. Enfermeira do Núcleo Multidisciplinar de Patologias Infecciosas na Gestação da UNIFESP/EPM

*** Enfermeira Obstetra. Doutor em Enfermagem. Professor Adjunto da Disciplina de Enfermagem Obstétrica do Departamento de Enfermagem da UNIFESP/EPM. Pesquisadora do CNPq
} 
crianças por transmissão perinatal, que foi descrita pela primeira vez nos Estados Unidos, em 1982 (CDC, 1982). No Brasil, os primeiros casos de transmissão perinatal foram notificados em 1985 no estado de São Paulo (BRASIL, 1995); desde então, a freqüência dessa categoria de transmissão vem aumentando, atingindo cerca de $90 \%$ dos casos de AIDS entre menores de 13 anos em 1998 (BRASIL, 1998a).

Segundo projeções da Organização Mundial da Saúde, cerca de 40 milhões de homens, mulheres e crianças estarão infectados pelo HIV no ano 2000, e a razão de infecção homem:mulher poderá ser de 1:1. As crescentes taxas de infecção encontradas na população feminina acompanham um aumento correspondente de infecções congênitas (MERTENS \& LOW-BEER, 1997).

Com o número crescente de mulheres infectadas em idade reprodutiva, as gestantes portadoras do HIV constituem uma situação especial para a assistência prénatal, tanto em relação ao desenvolvimento da gestação e do feto, quanto em relação aos aspectos psicológicos, sociais e familiares. Existem vários aspectos a serem observados, o assunto evolui à medida que as pesquisas acrescentam novos conhecimentos.

\section{DESENVOLVIMENTO}

O momento exato em que a infecção pelo HIV ocorre no feto não é conhecido, estudos sugerem que a transmissão pode ocorrer durante a gestação, parto ou pós-parto pelo aleitamento materno. A transmissão perinatal intra-útero foi comprovada pela detecção do HIV no líquido amniótico, tecidos fetais e placenta (SPRECHER et al., 1986; MUNDY et al., 1987). Segundo EHRNST et al. (1991) o risco de transmissão seria maior no final da gestação e no período intraparto. Os mecanismos da transmissão intraparto são desconhecidos mas, provavelmente, pode ocorrer pela exposição mucocutânea da criança ao sangue ou secreção cérvicovaginal materna (DUARTE, 1997; LUZURIAGA \& SULLIVAN, 1997).

A transmissão perinatal do HIV pelo aleitamento materno foi demonstrada por ZIEGLER et al. (1985), representando um risco adicional estimado em 14\% para as mulheres que já estavam infectadas na gestação (DUNN et al., 1992). A Organização Mundial da Saúde (WHO, 1992), recomenda para países que apresentam a desnutrição, diarréia e outras doenças infecciosas como as principais causas de mortalidade infantil, que sejam avaliados os riscos e benefícios para se desaconselhar o aleitamento materno. No Brasil, o Ministério da Saúde contra-indica o aleitamento materno entre as mulheres infectadas pelo HIV (BRASIL, 1995; 1998b).
As taxas de transmissão perinatal variam de 13 a $40 \%$, de acordo com a prevalência e fatores associados (CDC, 1995). Os fatores maternos que podem estar relacionados ao aumento do risco de transmissão perinatal incluem a doença materna avançada, a baixa contagem de CD4+ e o aumento da carga viral, bem como, corioamnionites, doenças sexualmente transmissíveis (DSTs), prematuridade (CDC, 1995) e a ruptura das membranas amnióticas por mais de quatro horas antes do parto (CONNOR et al., 1994; LANDESMAN et al., 1996). Alguns estudos, não conclusivos, sugerem que a realização de parto cesárea reduziria os riscos de transmissão intraparto (TOVO, 1993; CONNOR et al., 1994). Segundo MANDELBROT et al. (1998) a profilaxia com zidovudina (AZT) e a realização eletiva de parto cesárea diminuiria a incidência da transmissão perinatal do HIV.

Não está completamente estabelecido como a gestação poderia interferir na evolução da infecção pelo HIV. MINKOFF (1995), cita que a gestação, interferindo na resposta imunológica, poderia acelerar o desenvolvimento da AIDS. Em mulheres já imunocomprometidas, a gestação pode ser fator de risco na evolução da infecção pelo HIV (DUARTE, 1997; LANDERS et al., 1997).

As complicações da infecção pelo HIV na gestação, tais como abortamentos, baixo peso ao nascer, trabalho de parto prematuro, podem estar relacionadas, também, à presença de outros fatores, que por si só prejudicam o desenvolvimento da gestação, como o uso de drogas ilícitas, a presença de outras infecções associadas e a desnutrição (TEMMERMAN et al., 1994; DUARTE, 1997).

A sorologia para detecção da infecção pelo HIV tem sido recomendada como exame de rotina nos serviços pré-natais (MINKOFF et al., 1988). No entanto, deve ser voluntária e após informação sobre os benefícios do diagnóstico precoce para instituição de medidas de redução das taxas de transmissão perinatal (CDC, 1995). No Brasil, a Coordenação Nacional de DST/AIDS recomenda que seja oferecido o teste anti-HIV para todas as gestantes, mediante o seu consentimento, com aconselhamento pré e pós-teste, independente de apresentar situação de risco para a infecção pelo HIV (BRASIL, 1998b).

O diagnóstico laboratorial da infecção pelo HIV nas gestantes não é diferente daquele realizado em outros grupos. Para que se considere a gestante, HIV positivo, é necessária a avaliação laboratorial de duas amostras de sangue em datas diferentes e analisadas por métodos diferentes (BRASIL, 1995).

No Brasil, o Ministério da Saúde, tendo em vista evitar erros nos resultados dos testes laboratoriais para $\mathrm{o}$ diagnóstico sorológico do HIV, determinou recentemente, 
como primeira etapa, a realização de dois testes distintos, antígenos ou método laboratorial, pelo menos um deles, utilizando, também, antígenos HIV-2. As amostras com resultados contraditórios ou reagentes deverão ser submetidas a um teste complementar confirmatório, Imunofluorescência Indireta ou Western Blot, e nos casos com resultados positivos, é obrigatória a repetição da seqüência de testagem em nova amostra de sangue. As amostras com resultados negativos ou indeterminados nos testes confirmatórios deverão ser investigadas quanto à presença de anticorpos anti HIV-2, sendo recomendada a coleta de nova amostra após 30 dias, com o propósito de verificar a ocorrência de soroconversão recente. Para os neonatos, a detecção de anticorpos não caracteriza infecção pelo HIV devido à transferência passiva desses anticorpos pela placenta (BRASIL, 1998c).

Como terapias anti-virais empregadas atualmente para o tratamento da AIDS, temos as drogas inibidoras da enzima transcriptase reversa, entre elas o AZT, e as inibidoras da protease, uma enzima necessária para a clivagem da cadeia protéica e formação das proteínas virais (MINKOFF \& AUGENBRAUN, 1997). O AZT é capaz de inibir os efeitos citopáticos causados pelo HIV. Sua ação pela inibição da enzima transcriptase reversa e incorporação à síntese do DNA, inibe a replicação do vírus (MAMEDE, 1993).

O uso do AZT durante a gestação foi recomendado pelos CDC, em 1994, baseado nos resultados de um estudo multicêntrico (Estados Unidos e França), casualizado, placebo-controle, (AIDS Clinical Trials Group-protocol 076 - ACTG protocolo 076), que apontou a redução de dois terços das taxas de transmissão perinatal. A administração do AZT, durante a gestação, foi feita por via oral na dosagem de $500 \mathrm{mg} /$ dia e, durante o trabalho de parto, sob a forma endovenosa, $2 \mathrm{mg} / \mathrm{Kg}$ no período de uma hora, seguindo-se por infusão contínua de $1 \mathrm{mg} / \mathrm{kg} /$ hora até o momento do parto. Para o neonato, o AZT foi administrado na forma oral, na dosagem de 2 $\mathrm{mg} / \mathrm{kg}$ cada 6 horas, iniciando-se após 12 horas do nascimento até 6 semanas de vida (CDC, 1994). A redução da carga viral materna e da exposição do feto ao vírus, associada à passagem placentária do $\mathrm{AZT}$, poderia explicar a diminuição das taxas de transmissão perinatal durante a gestação e parto (CONNOR et al., 1994).

As gestantes que estiverem sendo medicadas com AZT, precisam ser avaliadas por meio de exames laboratoriais periódicos, com objetivo de detectar possíveis alterações hepáticas e anemia associadas ao regime terapêutico e contagem de CD4 para determinar a profilaxia das infecções oportunistas (CDC, 1994). Não são indicados procedimentos invasivos para avaliar maturidade e vitalidade fetal, já que poderiam aumentar o risco de transmissão perinatal (DUARTE, 1997).

Não estão totalmente explicados os efeitos adversos, para a mulher e para o feto, do uso de AZT durante a gestação, como o desenvolvimento de cepas resistentes, o potencial carcinogênico e os efeitos no desenvolvimento neurológico e no sistema reprodutivo (MINKOFF \& AUGENBRAUN, 1997). Portanto, a gestante deve ser informada dos benefícios e possíveis riscos do tratamento, aceitando ou não as recomendações terapêuticas. A recusa não deve modificar a assistência prestada (CDC, 1994).

Outros regimes terapêuticos anti-retrovirais têm sido estudados, mas os resultados relativos à transmissão perinatal e à toxicidade fetal, ainda não são completamente conhecidos. Não existe padronização do tratamento anti-retroviral a ser introduzido na vigência de infecção pelo HIV na gestação. Tem sido recomendada uma avaliação periódica e contínua durante a gravidez, dos benefícios e riscos, a curto e longo prazos, para a gestante e o feto, que subsidiará a decisão de escolha da terapêutica, sua continuidade ou modificação na gravidez (US PUBLIC HEALTH SERVICE, 1998).

Segundo recomendações da Coordenação Nacional de DST/AIDS, o AZT deve ser oferecido às gestantes portadoras do HIV durante o pré-natal após a $14^{\mathrm{a}}$ semana de gestação, dada sua eficácia na redução da transmissão vertical. A associação às outras terapias antiretrovirais, inclusive inibidores de protease, dependerá da avaliação clínica e laboratorial da gestante que, também neste caso, deverá ser informada sobre os potenciais riscos/benefícios da manutenção, modificação ou suspensão do tratamento (BRASIL, 1998b).

A freqüência das consultas pré-natais da gestante portadora do HIV, tem as mesmas recomendações de outros grupos, mensais até a $32^{\mathrm{a}}$ semana de gestação, quinzenais até a $36^{\mathrm{a}}$ e semanais até o parto, salvo diante de necessidades individuais e intercorrências, obstétricas ou clínicas (BRASIL, 1995). Destacamos ainda, a importância do atendimento realizado por equipe multiprofissional, médico, enfermeira, assistente social e psicóloga, dando assistência integral à gestante portadora do HIV.

\section{CONSIDERAÇÕES FINAIS}

Apesar dos resultados favoráveis no controle da doença, com a administração das terapias medicamentosas, anti-retrovirais e inibidores de protease, a cura da AIDS continua sendo um desafio para os cientistas no mundo inteiro. Muitas conquistas foram alcançadas desde o reconhecimento da doença, as novas opções de medicamentos têm prolongado e melhorado a qualidade de vida dos indivíduos portadores, mas medicamentos curativos ainda não foram desenvolvidos. 
No momento, a prevenção é o único meio de controle da propagação dessa infecção e os programas de saúde concorrem para diminuir as taxas de incidência. Apesar disso, a infecção continua atingindo toda a população, de maneira indiscriminada. Predominam, entre os novos casos, os meios de transmissão em que o comportamento pessoal foi responsável pela infecção, como os usuários de drogas endovenosas e as relações sexuais sem barreira de proteção.

Entre as mulheres, o principal fator de risco para a infecção pelo HIV têm sido as relações sexuais sem barreira de proteção e, segundo FOWLER et al. (1997), a maioria dos estudos apontam que a transmissão homemmulher seria mais eficiente quando comparada à transmissão mulher-homem. Considerando as desigualdades sociais aceitas para os homens e para as mulheres em relação à sexualidade, muitas vezes a mulher tem dificuldade de solicitar ao parceiro a utilização do preservativo. $\mathrm{O}$ condom feminino pode oferecer maior independência para as mulheres, tanto para a prevenção da transmissão do HIV como de uma gravidez indesejada, porém, sua aceitabilidade é ainda limitada, entre outros fatores, pelo alto custo.

O diagnóstico laboratorial para HIV em gestantes, a utilização de anti-retrovirais para a gestante e o recém-nascido, e o não aleitamento materno são estratégias utilizadas para a redução da transmissão perinatal do HIV, mas devem ser acompanhadas da identificação de fatores culturais, psicológicos e sociais que podem interferir na aceitação e aplicação das mesmas. No Brasil, em relação ao perfil sócio-econômico das mulheres portadoras do HIV, verifica-se desde 1987 a predominância de casos entre aquelas com baixa ou nenhuma escolaridade, atingindo $78 \%$ das ocorrências em 1994 (BRASIL, 1998a), o grau de escolaridade pode influir no nível de compreensão das intervenções necessárias para a assistência, bem como, dificultar o acesso às atividades melhor remuneradas.

São inúmeros os desafios encontrados, o assunto evolui rapidamente, sendo necessária a atualização constante para a assistência de enfermagem e a prática profissional, que constitui a aplicação de ações e de informações científicas com objetivo da prevenção e tratamento, em equipe multidisciplinar de assistência, um processo que envolve o aprendizado individual e coletivo, motivador da compreensão e da consciência para o estabelecimento de estratégias fundamentadas no conhecimento.

Portanto, os serviços de saúde devem estar organizados para esse atendimento e a enfermeira obstetra, bem como os outros profissionais da equipe prénatal, está envolvida na busca de soluções para as transformações que a infecção pelo HIV trouxe para a assistência à saúde da gestante, do feto e da família.

\section{REDUCTION OF HIV VERTICAL TRANSMISSION: A CHALLENGE FOR NURSING CARE}

With the crescent rates of HIV infection within female population in reproductive age, we may observe a correspondent increase in congenital infections. Thus, the obstetric nurse must be updated to participate and to develop programs of pre-natal care for HIV pregnant women. The purpose of this study was to review the pre-natal follow-up of this population regarding nursing care. Authors did not intend to approach all aspects of this subject, especially considering that investigations extend the great improvements already achieved since the acknowledge of the disease.

KEY WORDS: HIV, acquired immunodeficiency syndrome, pre-natal care, obstetric nursing

\section{REDUCCIÓN DE LA TRANSMISIÓN VERTICAL DEL SIDA: DESAFÍO PARA LA ASISTENCIA DE ENFERMERÍA}

Con las crecientes tasas de infección por el VIH en la población femenina en edad fértil, podemos observar el aumento correspondiente de infecciones congénitas. La enfermera obstétrica debe, por lo tanto, estar actualizada para la participación y el desarrollo de programas de asistencia prenatal a mujeres embarazadas infectadas con VIH. Este trabajo tuvo como objetivo ofrecer una revisión sobre el acompañamiento prenatal de esta población para la asistencia de enfermería. No se pretende agotar este asunto, una vez que pesquisas amplian los enormes avances ya ocurridos desde el reconocimiento de la enfermedad.

TÉRMINOS CLAVES: VIH, síndrome de inmunodeficiencia adquirida, atención prenatal, enfermería obstétrica 


\section{REFERÊNCIAS BIBLIOGRÁFICAS}

01. BRASIL. Ministério da Saúde. Secretaria de Assistência à Saúde. Programa Nacional de Doenças Sexualmente Transmissíveis/AIDS. Considerações gerais do binômio: HIV/AIDS e gravidez. Brasília: Programa nacional de DST/ AIDS, 1995. 48p.

02. . Ministério da Saúde. Secretaria de Projetos Especiais de Saúde. Coordenação Nacional de DST/AIDS. Boletim epidemiológico AIDS, Brasília, v. 11, n. 4, set./nov. 1998a.

03. Ministério da Saúde. Secretaria de Projetos Especiais de Saúde. Coordenação Nacional de DST/AIDS. Recomendação para a redução da transmissão vertical. [online]. 1998b. Available from World Wide Web: <URL:http:// www.AIDS.gov.br/assistência/folder htm> [08 set 1998].

$04 . \quad$ Ministério da Saúde. Secretaria de Vigilância Sanitária. Portaria $\mathrm{n}^{\circ} 488$, de 17 de junho de 1998. Diário Oficial da União. Seção 1, 18 de junho, 1998c. p. 3-4.

05. CDC. Centers for Disease Control and Prevention. Unexplained immunodeficiency and opportunistic infections in infants. MMWR, v. 31, n. 49, p. 665-667, 1982.

06. Recommendations of US Public Health Service Task Force on the use of Zidovudine to Reduce Perinatal Transmission of Human Immunodeficiency Virus. MMWR, v. 43, n. RR11, p. 1-20, 1994.

07. Recommendations for human immunodeficiency virus counseling and voluntary testing for pregnat woman. MMWR, v. 44, n. RR7, p. 1-15, 1995.

08. CONNOR, E.M. et al. Reduction of maternal-infant transmission of human immunodeficiency virus type-1 with zidovudine treatment. N. Engl. J. Med., v. 331, n. 18, p. 1173-1180, 1994.

09. DUARTE, G. Síndrome da imunodeficiência adquirida: aspectos obstétricos. In: MONTELEONE, P.P.R.; VALENTE, C.A. Infectologia e ginecologia e obstetrícia. São Paulo: Atheneu, 1997. p. 198-218.

10. DUNN, D.T. et al. Risk of human immunodeficiency virus type 1 transmission through breast feeding. Lancet, v. 340, n. 8819, p. 585-588, 1992.

11. EHRNST, A. et al. HIV in pregnant woman and their offspring: evidence for late transmission. Lancet, v. 338, n. 8760, p. 203-207, 1991.

12. FOWLER, M.G; MELNICK, S.L.; MATHIESON, B.J. Women and HIV-epidemiology and global overview. Obstet. Gynecol. Clin. North Am., v. 24, p. 705-729, 1997.
13. LANDERS, D.V.; TEJADA, B.M.; COYNE, B.A.

Imunology of HIV and pregnancy: the effects of each on the other. Obstet. Gynecol. Clin. North Am., v. 24, n. 4, p. 821-831, 1997.

14. LANDESMAN, S.H. et al. Obstetrical factors and the transmission of human immunodeficiency virus type 1 from mother to child. N. Engl. J. Med., v. 334, n. 25, p. 1617-1623, 1996.

15. LUZURIAGA, K.; SULLIVAN,J.L. Transmission of the human imunodeficiency virus from mother to the fetus and infant. In: DeVITA Jr., V.T.; HELlman, S.; ROSENBERG,S.A. AIDS: biology, diagnosis, treatment and prevention. Massachusetts: Lippincott, 1997. p.167-173.

16. MAMEDE, J.A.V. Ação da zidovudina (AZT) e ou aciclovir (ACV) durante a prenhez da rata albina (Rattus Norvegicus Albinus): ensaio biológico. São Paulo, 1993. Tese (Mestrado) Escola Paulista de Medicina.

17. MANDELBROT, L. et al. Perinatal HIV-1 transmission. JAMA, v. 280, n. 1, p. 55-60, 1998.

18. MARIN, H.F.; PAIVA, M.S.; BARROS, S.M.O. AIDS e enfermagem obstétrica. São Paulo: EPU, 1991. p. 1-33.

19. MERTENS, T.E.; LOW-BEER, D. Hacia donde se encamina la epidemia de infección por VIH e sida?. Rev. Panam. Salud Publica, v. 1, n. 3, p. 220-229, 1997.

20. MINKOFF, H.L. Síndrome da Imunodeficiência Adquirida. In: CHARLES, D. Infecções obstétricas e perinatais. Porto Alegre: Artes Médicas, 1995. p. 226-238.

21. MINKOFF, H.L.; AUGENBRAUN, M. Antiretroviral therapy for pregant women. Am.J. Obstet. Gynecol., v. 176, n. 2, p. 478-489, 1997.

22. MINKOFF, H.L. et al. Routinely offered prenatal HIV testing. N. Engl. J. Med., v. 319, n. 15, p. 1018, 1988.

23. MUNDY, D.C. et al. Human immunodeficiency virus isolated from amniotic fluid. Lancet, v. 2, n. 8556, p. 459-460, 1987.

24. SPRECHER, S. et al. Vertical transmission of HIV in 15 week fetus. Lancet, v. 2, n. 8501, p. 288, 1986.

25. TEMMERMAN, M. et al. Maternal human immunodeficiency virus-1 infection and pregancy outcome. Obstet. Gynecol., v. 83, n. 4, p. 495501, 1994.

26. TOVO, P-A. Cesarean section and perinatal HIV transmition:what next?. Lancet, v. 342, n. 8872, p. 630, 1993. (Commentary)

27. TURGEON, M.L. Acquired immunodeficiency syndrome (AIDS). In: Immunology e serology in laboratory medicine. 2. ed. Missouri: Mosby-Year Book, 1996. p. 295-313. 
28.US PUBLIC HEALTH SERVICE. Recommendations for use of antiretroviral drugs during pregnancy for maternal health and reducion of perinatal transmission of human immunodeficiency virus type 1 in the United States. [online]. Office of Public Health and Science. Clinical care for HIV guidelines. 1998. Available from world wide web: <URL: http://www.healthcg. com/hiv/treatment/ pregnancy/ print.html $>$ [19 Maio 1998]. p. 1-29.
29. WHO. WORLD HEALTH ORGANIZATION Global programme on AIDS. Consensus statment from WHO/UNICEF consultation on HIV transmission and breast-feeding. Wkly. Epidemiol. Rec., v. 67, n. 24, p. 177-179, 1992.

30. ZIEGLER,J.B. et al. Postnatal transmission of AIDS associated retrovirus from mother to infant. Lancet, v. 1, n. 8434, p. 896-898, 1985. 